\title{
Relationship between Attitudes toward Mental Illness, Self Esteem and Studying Psychiatric Course among Nursing Students
}

\author{
Hanaa Hamdy Ali El-Zeiny ${ }^{(1)}$. \\ Lecturer of Psychiatric Health Nursing, Faculty of Nursing, Zagazig University ${ }^{(l)}$.
}

\begin{abstract}
Nursing students are future health manpower. In order to fulfill nursing role, nursing students need to be trained in such a way to develop positive attitudes toward needy people and having high self-esteem. Aim:ToassessRelationship between attitudes toward mental illness, self esteem and Studying Psychiatric Course among Nursing Students.
\end{abstract}

Design: Descriptive correlation, "Comparative (Case control study)" design was used to conduct this study. Setting: Faculty of Nursing, Zagazig University.

Sample: A purposive sample consisted of 200 students divided into two equal groups (100 a psychiatric group and 100 a non psychiatric group).

Tools: A structured interview questionnaire covering demographic characteristics, attitude about mental illness scale, self-esteem scale.

Results: The study findings revealed statistically significant relationsbetween positive attitude and psychiatric study group. The positive attitude is higher among psychiatric study group (62.0\%). There were no statistically significant relations regarding self-esteem between two groups.

Conclusion:psychiatric course made some effect on attitudes towards mental illness but had no effects on selfesteem among nursing students.

Recommendation: the study recommended suggestions to develop psychiatric course so that it can enhance attitudes and self-esteem among nursing students.

Keywords: Attitudes toward mental illness, Nursing students, Self-esteem..

\section{Introduction}

Persons with mental disorders represent a considerable proportion of the world's population. It is estimated that about one million people die due to suicide every year and one in four people worldwide will experience mental illness in her or his lifetime. Psychiatric disorders have become a global burden the world over and account for $12.3 \%$ of the total global disease burden [34] Mental health has been hidden behind the curtain of stigma and discrimination for long time, according to the WHO report psychiatric disorders are now among the top ten causes of economic burden of diseases [5].

people who have or are perceived to have mental disorders may find it difficult to access services due to stigma and discrimination and these reactions obstruct prevention and treatment efforts and intensify the impact of the mental health disabilities. Both psychiatric nurses and psychiatric patients suffered from the same stigma [36]. Reducing stigma requires a change in behavior and attitudes toward acceptance, respect and equitable treatment of people living with mental illnesses (Mental Health Commission of Canada [1].

The university is the most important stage of education, which represents the crest of the educational pyramid and is designed to prepare individuals in an organized and directed for life, so that higher education level receives a lot of care and concern in most developed countries alike, to the important serious role [35].

Students starting the nursing course bring stereotypes and prejudice in relation to mentally-ill people, thus showing lack of knowledge as to their possibilities of recovery and social living. Available evidence clearly demonstrates that under graduate nursing students typically hold unfavorable attitudes toward mental illness and psychiatric/mental health nursing as a career [29].

An attitude is "a relatively enduring organization of beliefs, feelings, and behavioral tendencies towards socially significant objects, groups, events or symbols"; attitude is a psychological tendency that is expressed by evaluating a particular entity with some degree of favor or disfavor" (Mcleod, 2014). It was stated that attitude is the "sum of all the emotions and feelings experienced during the learning phase of the studied subject" [9].

Self-esteem is one of the strongest research topics in psychology [10]. Self-esteem is overall evaluation of one's worth or value and an important predictor of stress coping. Self-esteem is an important personality trait for healthcare professionals including nursing [3]/

In order to have the highest potentiality, students should have a positive attitude on selves and the surrounding environment should have a high self-esteem in order to succeed in duties and profession. Therefore, the need for making changes in the process of learning to promote the efficiency of nursing internship is essential [18]. 
High self-esteem can begin to develop when the acceptance of all individuals and group contributions are recognized and applauded, especially in a multi-culturally diverse world. Self -esteem is the one key ingredient that affects the level of proficiency in all fields of endeavor. Self-esteem has been correlated to: job success, school achievement, interpersonal compatibility, and general happiness [23].

High self-esteem in Healthcare professionals (HCP) naturally enhances the participation in social welfare and healthcare management. From a general perspective, a high self-esteem causes better performance and interpersonal success in turn leading to improved happiness and a healthier lifestyle. HCP with high selfesteem tend to inspire, motivate and induce a positive well-being both in the healthcare team and in patients with chronic or terminal illness [3].

Many psychological problems such as depression and suicide occur as a result of low self-esteem .College students with a low self-esteem tend to be unhappy, less sociable, more likely to abuse drugs, and are more vulnerable to depression, which are all correlated with lower academic achievement [17].

To give a boost to one's self-esteem, recognize and embrace positive qualities; one should make a list of all assets including skills, experiences, physical and social resources, talents, and anything else that makes one feel good and add to the list the compliments that others have given as well, reminding of all these assets is a sure confidence booster [31].

\section{Significance of the study}

Nursing students today are the nucleus of professional nurses of tomorrow. In order to ensure competent and safe practice, it is necessary for them to be individuals with high self-esteem. Some of these nursing students will work as a psychiatric nurses it's important for them to have positive attitudes toward mental illness.

A limited amount of research has been conducted attitudes toward mental illness and self esteem. Therefore this study was designed to compare attitudes and self-esteem between psychiatric and non-psychiatric nursing students.

\section{Settings:}

The study was conducted at the faculty of Nursing, Zagazig University.

\section{Sample:}

A purposive sample of subjects consisted of 200 nursing students fulfilled these criteria in the setting. They were divided into two equal groups of 100 subjects each:

- Study group (psychiatric group): the students in this group attended the psychiatric course along the semester.

- Control group (Non psychiatric group): for comparison, these were the students that study nursing community course during the semester.

\section{The sample was recruited according to the following criteria:}

- Both sexes (male \& female).

- Agreed to participate in the study.

- Never study formal nursing education in psychiatric before.

- Never has practice regarding psychiatric patients before.

- Complete attendance of psychiatric course without effective absence (for case study group).

Tools of data collection:Three tools were used

\section{Interview questionnaire form (Appendix 1):}

This included information about the personal and family history of the studied subjects, it composed of 25questions, included many items as age, sex, marital status, residence, father education, mother education and mass media present in house.

\section{Attitude about Mental Illness Scale (Appendix II):}

This scale was updated and developed by [8], that based on $\mathrm{Ng}$ and Chan, [20] attitude scale. The original scale consisted of 34 items and used to assess attitude about mental illness among Chines. (14 items) are omitted from it, because they were not relevant to e Egyptian culture, and (11 items) were added to fit variables under study. The current tool consisted of 31 items and divided into 5 categories to obtain details information about:

- Separatism, (6) items.

○ Stereotyping, (2) items. 
○ Benevolence, (8) items.

- Pessimistic prediction, (7) items.

$\circ \quad$ Stigmatization, (3) items.

\section{Scoring system:}

Responses were measured in all questions on three points Likert scale:

○ Agree was scored (3).

$\circ \quad$ Uncertain scored as (2).

○ Disagree scored as (1).

EXCEPT:questions number 1, 2 in Separatism subscale, question number 2 in stereotyping subscale \& questions number 1, 2, 3, 4, 5, 6, 8 in benevolencesubscale are reverse questions(Agree was scored(1) \&Disagree was $\operatorname{scored}(3)$.

\section{Total Score:}

- Negative attitude $<60 \%$ of total attitude score.

- Positive attitude $\geq 60 \%$ of total attitude score.

\section{Self-Esteem Scale (Appendix III):}

This involved questions about Self-Esteem Scale. This scale was originally developed by Hudson (1994), to measure problems of personal self evaluations. It was translated into Arabic language by [7], it is a valid and reliable measure of self esteem on a sample of faculty students ( $r=.92)$ [27]. The scale is composed of 24 items.

\section{Scoring system:}

Responses were measured on three points Likert scale that were scored for all items of the scale as:

- Never was scored as (1).

- Sometimes was scored as (2).

○ $\quad$ All the time was scored as (3).

\section{Total self esteem score was calculated as:}

- Low self esteem $<60 \%$ of total self esteem score.

○ High self esteem $\geq 75 \%$ of total self esteem score.

\section{Preparatory phase:}

\section{Operational design}

A review of the past, current related literature, covering various aspects of psychiatric course, attitudes, self esteem of nursing students was done using available books, articles periodicals magazines, and internet search, to get acquainted with the research problem and develop the study tools.

\section{Pilot study:}

Before performing the main study, a pilot study was carried out on a number of $4^{\text {th }}$ year nursing students whose number was about $10 \%$ of the study sample. The purpose of pilot was to test the questions for any ambiguity, and to assess the practicability and feasibility of using the structured interview questionnaire form for the nursing students. It also helped the researcher to determine the time needed for filling out the forms. Those who shared in the pilot included in the main study sample.

\section{Field work}

- The tool construction phase:

Performance scale was taken up one month (September, 2014) to be constructed.

- The preparatory phase:

It was done by obtaining an official permission from the Dean of the Faculty of Nursing for the approval to conduct the study and get access to $4^{\text {th }}$. year nursing students' list of numbers from College Administration Department. Then, obtaining a list of the numbers of the $4^{\text {th }}$. year nursing students in the first semester of the studied year (2014-2015); it contained the total number of the students; the number of (females, males, failed students; students that came from the Technical Institute of Health and the others from secondary school).

- The Actual phase:

It was executed by two stages taking two weeks, each stage took one week. Those who agreed to participate were given the tool and asked to fill it out and return it anonymously in the same setting.

The first stage of the study was at the beginning of the month of October, the beginning of the first semester. During this week, the researcher contact with the nursing students that study community health 
nursing (the control group "non psychiatric group" in the study) to clarify the objective of the study and the applied methodology and giving the same instructions; each student was given the opportunity to fill-in the scales under guidance and supervision of the researcher to answer any question to avoid omitting any items of tool such as defining the meaning of any items of the scales. The time when the tools were distributed to the subjects ranged from (10A.M) to (1P.M). The time needed to fill the tools ranged from 10 to 15 minutes.

The second stage of the study was done after the students (psychiatric group) had completed the studying of the course by the end of the semester. During the second week of December, the tools were given to the psychiatric study group with the same steps and instructions that done with the first group (non-psychiatric study group). The time when the tools were distributed to the subjects ranged from (10A.M) to (1P.M). The time needed to fill the tools ranged from 10 to 15 minutes.

\section{Ethical Considerations:}

All ethical issues were taken into consideration during all phases of the study. Prior to the initial interview, verbal explanation of the nature and the aim of the study have been explained to all nursing students included in the study sample. The study protocol was approved by the pertinent authority. Orally agreement for participation of the subjects was taken from the participants. They were given an opportunity to refuse or to withdraw at any phase if they want without any reasons and they were assured that the information that was taken from them would be confidential and used for the research purpose only.

\section{ADMINISTRATIVE DESIGN}

An official permission was obtained from the Dean of the Faculty of Nursing to obtain their permission for data collection.

\section{STATISTICAL DESIGN}

After completion of data collection, the data were organized and tabulated, statistically analyzed using Data entry was done using Epi-Info 6.35 computer software package, while statistical analysis was done using SPSS 21.0 statistical software package. Data were presented using descriptive statistics in the form of frequencies and percentages for qualitative variables, and means and standard deviations for quantitative variables.

\section{- Statistical methods:-}

\section{Data are summarizing using:}

- Arithmetic mean: as average describing the central tendency of observations.

- The Standard Deviation: as a measure of dispersion of results around the mean (for quantitative variables).

○ The number of observations: for each the percentage (for qualitative variables.

\section{The observed difference associated was considered as following:}

Qualitative variables were compared using qui square test $\left(\mathrm{X}^{2}\right)$ as the test of significance. The $\mathrm{p}$-value is the degree of significant and using independent $\mathrm{t}$ test to compare mean score between two groups. The p-value is the probability that an observed difference is due to chance and not a true difference. A significant level value was considered when $\mathrm{p}$-value $\leq 0.05$ and a highly significant level value was considered when $\mathrm{p}$-value $\leq 0.001$, while $\mathrm{p}$-value $>0.05$ indicates non-significant results.

\section{Results}

Table (1) the table shows that the mean age of studied sample was $21.7400 \pm .67600$ years in psychiatric group; the majority of the studied participants in both groups were females $71.0 \%$ \& $76.0 \%$ respectively.

Table (2) the table indicates that there was a highly significant relation between psychiatric study group and non psychiatric study group regarding students' reading about psychiatric illness as there was $88.0 \%$ of psychiatric study group compared with $59.0 \%$ of non psychiatric study group. In the same table it can be noticed that, there was a highly significant relation at $\left(\mathrm{P}<0.001^{* *}\right)$ between psychiatric and non psychiatric study group regarding students' knowledge about meaning of psychiatric illness as there were $90.0 \%$ of psychiatric study group, meanwhile in non psychiatric group, it decreased to reach $47.0 \%$

Table (3) the table denotes that there are highly statistically significant relations were found between positive attitude and psychiatric study group. The positive attitude is higher among psychiatric study group (62.0\%).

Table (4) the table reveals that, there were no statistically significant relations between them. However, one can notice that the score of low self esteem is higher among students in both psychiatric and non psychiatric study group. 
Table I:

\begin{tabular}{|c|c|c|c|c|c|c|}
\hline \multirow[t]{2}{*}{ Item } & \multicolumn{2}{|c|}{ Psychiatric study group } & \multicolumn{2}{|c|}{$\begin{array}{l}\text { Non Psychiatric } \\
\text { study group }\end{array}$} & \multirow[t]{2}{*}{$\chi^{2}$} & \multirow{2}{*}{$\begin{array}{c}\mathrm{P}- \\
\text { value }\end{array}$} \\
\hline & No & $\%$ & No & $\%$ & & \\
\hline \multicolumn{5}{|l|}{ Age } & \multirow[t]{5}{*}{1.87} & \multirow[t]{5}{*}{$>0.05$} \\
\hline $20-$ & 9 & 9.0 & 9 & 9.0 & & \\
\hline $21-$ & 31 & 31.0 & 40 & 40.0 & & \\
\hline $22-23$ & 60 & 51 & 60.0 & 51.0 & & \\
\hline Mean +SD & \multicolumn{2}{|c|}{$21.7400 \pm .67600$} & \multicolumn{2}{|c|}{$21.2500 \pm .43519$} & & \\
\hline Gender & & & & & \multirow[t]{3}{*}{0.642} & \multirow[t]{3}{*}{$>0.05$} \\
\hline Female & 71 & 71.0 & 76 & 76.0 & & \\
\hline Male & 29 & 29.0 & 24 & 24.0 & & \\
\hline \multicolumn{5}{|l|}{ Marital status } & \multirow[t]{3}{*}{0.099} & \multirow[t]{3}{*}{$>0.05$} \\
\hline Single & 73 & 73.0 & 71 & 71.0 & & \\
\hline Married & 27 & 27.0 & 29 & 29.0 & & \\
\hline \multicolumn{5}{|l|}{$\begin{array}{l}\text { Residence during } \\
\text { study }\end{array}$} & \multirow[t]{4}{*}{1.17} & \multirow[t]{4}{*}{$>0.05$} \\
\hline University housing & 16 & 16.0 & 20 & 20.0 & & \\
\hline Family home & 71 & 71.0 & 71 & 71.0 & & \\
\hline Private home & 13 & 13.0 & 9 & 9.0 & & \\
\hline
\end{tabular}

Personnel

Characteristics of the Nursing Students $(n=200)$.

(*) Statistically significant at $\mathrm{p}<0.05$

Table 2: Personnel History of the Nursing Students $(\mathrm{n}=200)$.

\begin{tabular}{|c|c|c|c|c|c|c|}
\hline \multirow[t]{2}{*}{ Item } & \multicolumn{2}{|c|}{$\begin{array}{l}\text { Psychiatric } \\
\text { study group }\end{array}$} & \multicolumn{2}{|c|}{$\begin{array}{l}\text { Non Psychiatric } \\
\text { study group }\end{array}$} & \multirow[t]{2}{*}{$\chi^{2}$} & \multirow[t]{2}{*}{$P$ value } \\
\hline & No & $\%$ & No & $\%$ & & \\
\hline $\begin{array}{l}\text { Mass Media available at } \\
\text { home }\end{array}$ & & & & & \multirow[t]{5}{*}{6.85} & \multirow[t]{5}{*}{$<0.05^{*}$} \\
\hline TV & 3 & 3.0 & 8 & 8.0 & & \\
\hline Computer & 12 & 12.0 & 9 & 9.0 & & \\
\hline Receiver & 3 & 3.0 & 4 & 4.0 & & \\
\hline Net & 82 & 82.0 & 79 & 79.0 & & \\
\hline Meaning of psychiatric illness & & & & & \multirow[t]{3}{*}{44.68} & \multirow{3}{*}{$\begin{array}{c}<0.001 * \\
*\end{array}$} \\
\hline No & 10 & 10.0 & 53 & 53.0 & & \\
\hline Yes & 90 & 90.0 & 47 & 47.0 & & \\
\hline $\begin{array}{l}\text { Reading about psychiatric } \\
\text { illness }\end{array}$ & & & & & \multirow[t]{3}{*}{21.58} & \multirow[t]{3}{*}{$\begin{array}{c}<0.001 * \\
*\end{array}$} \\
\hline No & 12 & 12.0 & 41 & 41.0 & & \\
\hline Yes & 88 & 88.0 & 59 & 59.0 & & \\
\hline $\begin{array}{l}\text { Previous treatment of } \\
\text { psychiatric illness }\end{array}$ & & & & & \multirow[t]{4}{*}{0.113} & \multirow[t]{4}{*}{$>0.05$} \\
\hline No & 76 & 76.0 & 78 & 78.0 & & \\
\hline Yes & 24 & 24.0 & 22 & 22.0 & & \\
\hline Who was treated & & & & & & \\
\hline No & 76 & 76.0 & 78 & 78.0 & \multirow[t]{5}{*}{6.30} & \multirow[t]{5}{*}{$<0.05^{*}$} \\
\hline You & 0 & 0.0 & 4 & 4.0 & & \\
\hline Friend & 5 & 5.0 & 8 & 8.0 & & \\
\hline Nearest person & 12 & 12.0 & 7 & 7.0 & & \\
\hline Relative & 7 & 7.0 & 3 & 3.0 & & \\
\hline
\end{tabular}

(*) Statistically significant at $\mathrm{p}<0.05$

Table (3): Relations between Negative/Positive Attitude and Both Studied Groups ( $\mathrm{n}=200)$.

\begin{tabular}{|c|c|c|c|c|c|c|}
\hline \multirow[t]{2}{*}{ Total attitude score } & \multicolumn{2}{|c|}{$\begin{array}{l}\text { Psychiatric study } \\
\text { group }\end{array}$} & \multicolumn{2}{|c|}{$\begin{array}{l}\text { Non Psychiatric } \\
\text { study group }\end{array}$} & \multirow[t]{2}{*}{$\chi^{2}$} & \multirow[t]{2}{*}{$P$ value } \\
\hline & No & $\%$ & No & $\%$ & & \\
\hline Negative attitude & 38 & 38.0 & 77 & 77.0 & \multirow[t]{2}{*}{31.12} & \multirow{2}{*}{$\begin{array}{c}<0.001 \\
* *\end{array}$} \\
\hline Positive attitude & 62 & 62.0 & 23 & 23.0 & & \\
\hline
\end{tabular}

(*) Statistically significant at $\mathrm{p}<0.05$ 
Relationship between Attitudes toward Mental Illness, Self Esteem and Studying Psychiatric ....

Table (4): Relations between Low/High Self Esteem and Both Studied Groups ( $\mathrm{n}=200)$.

\begin{tabular}{|l|r|r|r|r|r|c|}
\hline \multirow{2}{*}{ Total self esteem score } & \multicolumn{2}{|c|}{$\begin{array}{c}\text { Psychiatric } \\
\text { study group }\end{array}$} & \multicolumn{2}{|c|}{$\begin{array}{c}\text { Non Psychiatric } \\
\text { study group }\end{array}$} & \multirow{2}{*}{$\chi^{\mathbf{2}}$} & \multirow{2}{*}{ P value } \\
\cline { 2 - 5 } & No & \% & No & \% & & \\
\hline Low self esteem & 74 & 74.0 & 83 & 83.0 & 2.40 & $>$ \\
\hline High self esteem & 26 & 26.0 & 17 & 17.0 & & \\
\hline
\end{tabular}

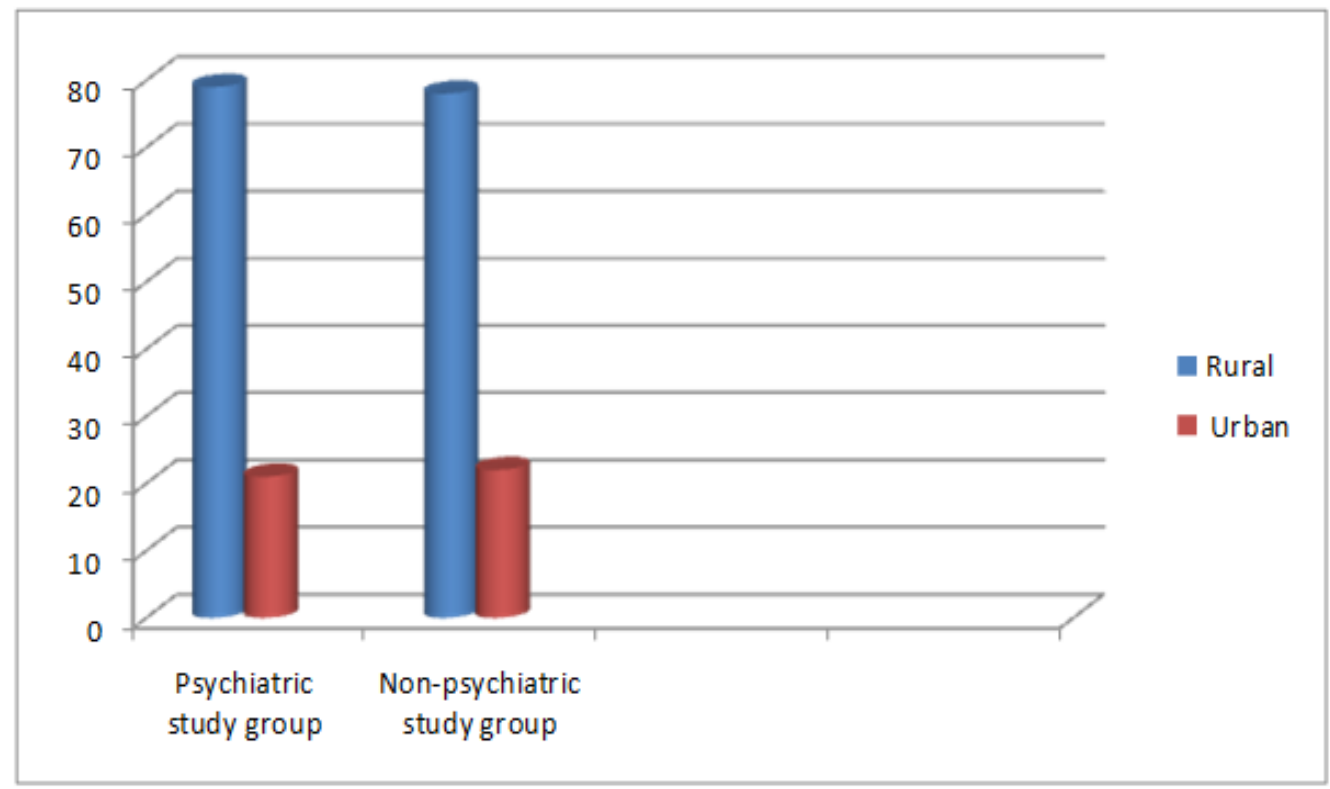

Fig. I: Personnel Characteristics of The Nursing Students Regarding Residence $(n=200)$.

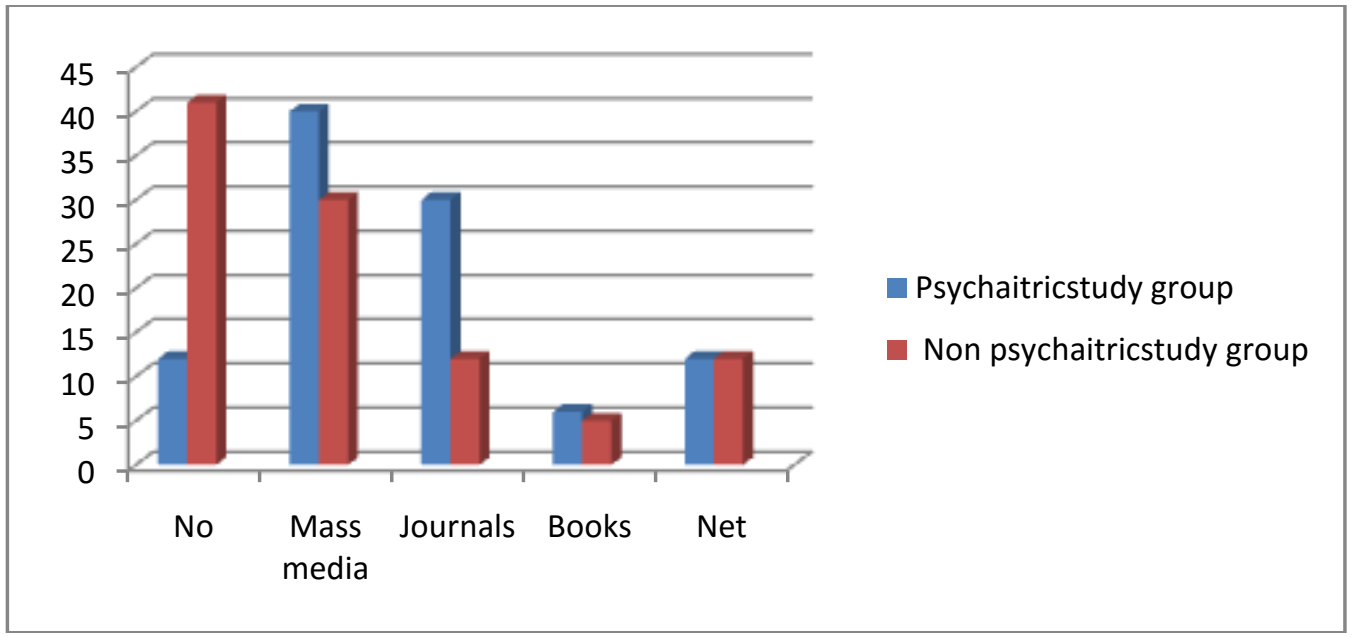

Fig 2: Students'Sources of Information about Mental Illness.

\section{Discussion}

Mental health problems are a major cause of lost years of quality life. In addition to that, mental disorders were the fifth leading cause of death and disease worldwide (Mercola, 2013). Education programs introducing nurses to mental health nursing lead to more favorable attitudes towards consumer participation[15]. Nursing education is a challenge in a developing country like Egypt [29].

Few studies in Egypt investigated problems for student nurses. However, this study mainly focused only on assessing and clarifying the problems, our study focused on comparing attitudes, self-esteem among psychiatric and non psychiatric nursing students.

Concerning personal characteristicsof the current study subjects the mean age of studied sample was $21.7400 \pm .67600$ years in psychiatric group,the majority of the studied participants in both groups were females $71.0 \%$ \& $76.0 \%$ respectively.

Regarding Personnel History of the Studied Nursing Students, according to the current study findings, revealed that most of the psychiatric group $(90.0 \%)$ knew the meaning of the mental illness and slightly less than half of the psychiatric study group (40.0\%), and third of the non psychiatric study group $(30.0 \%)$ gained 
their information about mental illness through mass media. Similar to these findings, A Jordan study done by Abo El magd\& Al Zamil, [1] found that more than one third of students (39\% \& 38\%) from medical and nonmedical students respectively gained their information about mental illness through mass media.Unlike these findings, Mansour [19] reported that the main source of information in his study were television and newspapers.

Concerning the residence of students, the result of the current study revealed that, most of the participants resided in rural. This finding might attributed to the setting of data collection in Zagazig University at El-Sharkia governorate which characterized by its agricultural nature and most of its cities are rural areas. This finding is in the same line with Omar et al., [26] who found in his study that more than half of the samples were resided in rural area. On the contrary, Poreddi et al. [29] found in their study that slightly more than half of the participants $(52.7 \%)$ came from urban.

African societies have a peculiar attitude towards the sick or mentally ill persons and this is evident in the rejection, scornful disposition and a negative perception of the sick individual [22]. It is well documented in the literature that undergraduate nursing students held more negative attitudes toward mentally ill people; other research studies have concluded that those negative attitudes can be positively impacted by proper nursing education [5].

Related to attitudes toward mental illnessamong psychiatric \& non- psychiatric group, fortunately the current study shows that the positive attitude is higher among psychiatric study group (62.0\%). This finding supports Gestsdóttirand Guðmundsdóttir, [11] who said in their study in University of Iceland thateducation on mental health is a successful strategy to improve knowledge and to reduce negative attitudes and misconceptions about mental health and mental illness, they also added that those who are more knowledgeable about mental illness are less likely to endorse stigma and discrimination as prejudice about mental illness has been shown to go hand in hand with ignorance; Additionally, providing correct information about mental illness can help reduce the fears, myths and mistaken beliefs that some people have about mental disorders.

This finding is consistent with that of Shaher\&Mudallal[30] who revealed in their study that students' attitudes towards mental illness were changed positively after taking the course. Also, Vijayalakshmi et al., [33] agree with this finding in their Indian comparative researchbetween nursing and business management students, they reported that the group that study an educational nursing psychiatric course (nursing students) generally hold more positive attitudes towards all aspects of mental illness than BBM students. In agreement with these current results, a result revealed by Gyllensten et al., [14] indicated that there was a significant improvement for the total group in their being afraid of people with mental illness in general and being more positive towards having mentally ill people living in their neighborhood and some educational features positively influencing stigmatizing attitudes were identified.

In contrary with our findings, Gulati et al., [13] stated in their Indian study thatexposure to psychiatry as per the current curriculum seems to have a limited influence in bringing a positive change in OMI and psychiatry. Like this disagreement, [15] reported in his study in South India that the undergraduate medical students have a very unfavorable attitude toward psychiatry and mentally ill patients.

This might be explained that Psychiatry is given very less importance in the Indian undergraduate medical curriculum and this affects the attitudes of students toward psychiatry and mentally ill patients as mentioned by the Indian researcher himself in his study we talked above.

Nursing is one of the stressful jobs in community that requires mental health at desired levels. Selfesteem is one of the most important factors in mental health that plays an important role in promotion of mental health that defined as the level of approval, acceptance and self-worth in relation to self. [12]The role of selfesteem as a moderator of stress, people having higher self-esteem in stressful situations have a higher sense of self-worth and self-efficacy that these consequences will function more effectively in these situations [27].

Unfortunately, the nursing psychiatric course education did not evidently improve self-esteem of the participants. The current results revealed that there were no statistically significant relations between psychiatric and non psychiatric study group. The majority $(74.0 \%)$ of the study in psychiatric study group reported low self esteem. This could be explained due to the educational course may be weak in enhancing self-esteem of student. The course stresses only on knowledge about psychiatric diseases and how to deal mental patients. No subjects interested in enhancing the personality of the students in the course despite the importance of enhancing levels of self-esteem.

This current result is in the same line with the result of [3] in their Indian study; they found that overall levels of self-esteem were low in the study sample of nursing students. Similarity, Edwards et al, [6] found in their English study at the United Kingdom that their sample of students had lower general self-esteem at the end of their training.

In contrast with our present study, Chaves et al, [2] reported in their Brazilian study that concerning the self-esteem level, 68\% presented high self-esteem, 30\% average and 2\% low. In the same line, Taha et al, [32] found that the majority of the students in the three countries had high self esteem (78\% in KSA, 96\% in Egypt 
and $84 \%$ in Yemen) while the rest of subjects had low self esteem (22\% of KSA students, $4 \%$ of Egypt students and $16 \%$ of Yemen students) with a highly statistically significant difference $(\mathrm{X} 2=13.953, \mathrm{p}=.001)$.

\section{Conclusion}

Based on the results of the present study it can be concluded that, fortunately, studying psychiatric course made some effect on attitudes towards patients with mental illness. It improves the attitudes of the nursing students' attitudes toward mental illness. To understand the effective educational ingredients for change, further research is needed. Unfortunately, the course didn't have an effect on self-esteem. More researches should be done to assess, develop and enhance self-esteem for the nursing students because of their importance.

\section{RECOMMENDATIONS}

Based on the study findings, the following recommendations are proposed:

Regarding attitudes towards mental illness:

- Despite the enhancing in the students' attitudes toward mental illness after studying the psychiatric course, more development should done included some chapters stress on changing attitudes positively.

- The clinical time during psychiatric course should be more than the present ones for more real contacting with mental patients.

Regarding self-esteem:

- The psychiatric nursing education should aim at enhancing the self-esteem of students giving the appropriate theoretical knowledge and skills required to practice as a nurse, noting the real dimensions of the role of the nurse and the difficulties involved in the exercise.

- Some chapters should be added to the course aiming to develop student's personality; this is will enhance nursing future in Egypt.

- Psychiatric department in the faculty should present training courses to develop personality of the students to prepare them to their future career.

Finally, the findings from this study highlight the need to develop the psychiatric course so that it can enhance the personality of the students. Also, Additional researches are needed to assess the attitudes toward mental illness, self-esteem .

\section{References}

[1]. M.H. Abo El magd\&L. Al Zamil, Medical and Non-Medical Female Students' Attitudes toward Mental Illness and Psychiatric Patientsat Umm Al Qura University. Life Science Journal. 10(2), 2013, 882-888.

[2]. E. Chaves ,, T. Simão,I. Oliveira ,I. Souza, D.Iunes\& D. Nogueira,Assessment of nursing students' selfesteem at a university in the South of Minas Gerais (Brazil). Invest EducEnferm. 31(2):261-269.

[3]. E. Chris ,M. Pais,S.P. Kumar ,\&V. Sisodia, Perceived Self-Esteem amongst First-Year Nursing Students - A Cross-Sectional Survey. International Journal of Health and Rehabilitation Sciences (IJHRS).2012 (1)2: 74.

[4]. M. Dako-Gyeke\& E. Sowah,Stigmatization and Discrimination Experiences of Persons with Mental Illness: Insights from a Qualitative Study in Southern Ghana. Social Work \& Society Journal; 2013, 1(11): 1.

[5]. E. Dawood , Impact of Clinical Placement on Nursing Students' Attitudes towards Psychiatry. Journal of American Science. 8(2): 2012, 627-632]. (ISSN: 1545-1003).

[6]. D. Edwards ,P. Burnard, K. Bennett \& U.Hebden, A longitudinal study of stress and self-esteem in student nurses. Nurse Education Today. 30(15): 2010, 78-84.

[7]. M. El-Desouky, Self-Esteem guidance. Egyptian Renaissance Library, 9 Adlystreet, Cairo 2004.

[8]. A. El-Sayed, Attitudes and beliefs about mental illness among adolescents in Zagazig .Faculty of Nursing. Zagazig University. (unpublished PDF) 2011.

[9]. A. Garcia-Santillan, E. Moreno-Garcia ,J. Carlos-Castro, H. Jorge, J.H. Zamudio-Abdala \&J. Gardunno-Trejo,Cognitive, Affective and Behavioral Components That Explain Attitude toward Statistics. Journal of Mathematics Research; 4(5), 2012, 8-9.

[10]. J.E. Gebauer, M. Riketta,P. Broemer,\&G.R. Maio, "How much do you like your name?" An implicit measure of global selfesteem.Journal of Experimental Social Psychology. 44(5), 2008, 1346-1354.

[11]. A.M. Gestsdóttir\&G.B. Guðmundsdóttir, Evaluation of school-based mental health promotion for adolescents Focus on knowledge, stigma, help-seeking behavior and resources. Thesis submitted for the degree of Master of Public Health Sciences. Faculty of Medicine.Centre of Public Health Sciences.School of Health Sciences.University of Iceland. Available at: http://skemman.is/stream/get/1946/6398/18206/1/Lokarverkefni-pdf.pdf, 2010.

[12]. S. Ghezelbash S., , F. Rahmani, H. Peyrovi, M.Inanloo\& S. Shekarchian, Comparison of Self-Esteem Among First to Fourth Year Nursing Students From Universities of Medical Sciences in Tehran. Published online. Available at: http://thritajournal.com/?page=article\&article_id=24336. Accessed on, 2015.

[13]. P. Gulati, S. Das\& B.S. Chavan, Impact of psychiatry training on attitude of medical students toward mental illness and psychiatry.Indian Journal of Psychiatry.56(3). 2014,: 271-277.

[14]. A. Gyllensten, B. Svensson, T. Björkman, L. Hansson, C.Leufstadius, U. Bejerholm,U. Markström, M. Östman, M. Eklund, D. Brunt \&M. Sandlund,Attitudes in Healthcare Students Towards Mental Illness - A Pre- and Post Multicenter University Program Survey. The Internet Journal of Allied Health Sciences and Practice. 9(3), 2011, 2-8.n

[15]. B.Happell , L.Moxham \& C. Platania-Phung , The impact of mental health nursing education on undergraduate nursing students' attitudes to consumer participation.Journal of Issues Mental Health Nursing.32(2), 2011, 108-13.

[16]. W. Hudson, Index of self-esteem. In Fisher J.Corcoarem K. Measure for clinical practice: A source book. 2nd ed. New York; Free press Co, 12994,: 283-4. 
[17]. A.I. Khalil, M.O. Abou-Hashish ,\&E.S. Dawood, Coeducation versus Single Sex Education: Impact on Self Esteem and Academic Achievements among Nursing' Students. Journal of American Science. 7(12), 2011, 177.

[18]. S. Lakdizaji, F. Abdollahzadeh, H. Hassankhanih\&M. Kalantari M. ,Impact of guided reciprocal peer questioning on nursing students' self-esteem and learning. Iranian Journal of Nursing and Midwifery Research. 18(4), 2013, 285.

[19]. A. Mansour, high schoolers' knowledge and attitudes about schizophrenia in Saudi Arabia. Alexandria Bulletin. 44(3), 2008, 316319 .

[20]. S. Mcleod,Attitudes and Behavior. Simply Psychology.Available at http://www.simplypsychology.org/attitudes.html. Accessed on, 2014.

[21]. J. Mercola, Mental Health Disorders Now Leading Cause of Non-Fatal Illness Worldwide. Available at: http://articles.mercola.com/sites/articles/archive/2013/09/12/mental-health-disorders.aspx. 2013.

[22]. S. Mohammed \& S.K. Mohammed, Attitudes towards mental illness in a Malay Army Battalion. Medical Journal of Asia. 7(2), 2008, 21-32.

[23]. H. Naderi, R. Abdullah , H.T. Aizan, J. Sharir\&V. Kumar V. . Self Esteem, Gender and Academic Achievement of Undergraduate Students. American Journal of Scientific Research. (3), 2009, 27.

[24]. Ng P., \& Chan K., , Sex Differences in opinion towards mental illness secondary school students in Hong Kong. International Journal of Social Psychiatry; 46 (2), 2000, 79.

[25]. S. Nikitha, T. Jose \& B.Valsaraj, A correlational study on academic stress and self-esteem among higher secondary students in selected schools of Udupi District. Nitte University Journal of Health Science. 4(1), 2014, 106.

[26]. A. Omar A., M. Abo El-Magd, I. Mohamad \& A.Darweesh, Nursing students' attitudes toward psychiatric nursing and psychiatric patients. Zagazig Nursing Journal. 7(2), 2011, 15-26.

[27]. B. Pastwa-Wojciechowska, M. Kazmierczak\&M. Blazek, Self-esteem and styles of coping with stress versus strategies of planning in people with psychopathic personality disorders. Med SciMonit.18(2), 2012, CR119-24.

[28]. V.Poreddi, R. Thimmaiah, D. Pashupu\& S. Badamath, Undergraduate Nursing Students' Attitudes towards Mental Illness: Implications for Specific Academic Education. Indian Journal of Psychological Medicine. 36(4), 2014, 368-372.

[29]. B. Ramachandra, R. Konduru\& S.Math,.Assessing the attitudes and perceptions towards nursing profession among nursing students.Nurs J India.103(1), 2012, 6-8.

[30]. H. Shaher\&R. Mudallal,Attitudes of Jordanian nursing students towards mental illness: The effect of teaching and contact on attitudes change. College Student Journal. 43(2), 2009, 235-248.

[31]. L. Sokol, Six Ways to Boost Your Self-Esteem. Available at https://www.psychologytoday.com/blog/think-confident-beconfident/201001/six-ways-boost-your-self-esteem.2010.

[32]. N Taha, E. Mansour, A. Sobhy\&E. M. Youness,Comparison between Body Image and Self-Esteem among Female Nursing Students in Three Different Arab Countries. Medical Journal of Cairo University.79(1), 2008.509-517.

[33]. P. Vijayalakshmi, D. Reddy, S.P. Math \& R. Thimmaiah, Attitudes of undergraduates towards mental illness: A comparison between nursing and business management students in India. The South African Journal of Psychiatry. 19(3), 2013, 66-73.

[34]. World Health Organization, , Mental health and development. Retrieved from http://www.who.int/topics/mental_health/en .2010.

[35]. H.M. Zan\&A.K. Khudhair, Impact of social phobia upon self-esteem of nursing collegians' in Iraq. Iraqi National Journal of Nursing Specialties.Special issue. (25), 2012,121.

[36]. Mental Health Commission of Canada [MHCC], STIGMA. Available http://www.mentalhealthcommission.ca/English/issues/stigma.2014 